\title{
Comparative Study of Cartilage Shield Tympanoplasty vs Temporalis Fascia Graft Tympanoplasty: A Retrospective Study
}

Tarun Ojha ${ }^{1}$, Anuj Kansara ${ }^{2}$, Vipasha Yogi ${ }^{3}$, Kunal Sharma ${ }^{4}$, Shreya Prasad $^{5}$

\begin{abstract}
Background: This study was conducted to demonstrate a comparative study about graft uptake rate and hearing gain between cartilage shield tympanoplasty (CST) and tympanoplasty with temporalis fascia (TF) in patients with chronic otitis media (tubotympanic disease).

Materials and methods: Cartilage shield tympanoplasty and TF tympanoplasty were studied in two groups. Group I containing 65 cases and group II having 80 cases with central perforations. Graft uptake rates and hearing improvement at 3 months postoperative follow-up were compared. Results: The graft uptake rates were 98.46 and $90 \%$ in groups I and II, respectively, at the end of 3 months. In total, $88 \%$ in group II and $90 \%$ in group I had improvement in hearing at 3 months of surgery.

Conclusion: Conchal cartilage can be used effectively as a graft material for cartilage shield tympanoplasty. It has also shown superior autograft as compared to TF, not only because of better graft uptake rates and less partial failure rates but also due to the significant hearing improvement, talking in terms of mean $A B$ gap in both types of graft materials.

Keywords: Cartilage, Cartilage shield tympanoplasty, Temporalis fascia, Tympanoplasty.

Journal of Mahatma Gandhi University of Medical Sciences \& Technology (2019): 10.5005/jp-journals-10057-0115
\end{abstract}

\section{INTRODUCTION}

As evidenced in the literature, cartilage shield tympanoplasty (CST) has shown to have better results all around the globe. Cartilage shield tympanoplasty has now become a popular alternative for surgeons to the traditional use of temporalis fascia (TF) to obtain incontrovertible success rates of tympanic membrane (TM) reconstruction. Nowadays, different surgical approaches, surgical techniques, and graft materials are in practice, of which TF has been most commonly used. ${ }^{1,2}$ Cartilage-perichondrium composite grafts are certainly considered to be one of the best materials for myringoplasty, especially in cases of large perforations where perforation consists of $>50 \%$ of the TM area, anteriorly placed perforations, adhesive otitis media, and/or recurrent perforations. ${ }^{3,4}$ However, acceptance of routine reconstruction of the TM with cartilage has been hampered as the cartilage is thick and there are concerns regarding compromise in hearing improvement with its use. Fascia grafts, on the contrary, are unstable which makes graft uptake results variable. Our present study was undertaken to compare the results of graft uptake rates combined with hearing improvement, in patients planned for primary tympanoplasty using either TF as compared to cartilage with its perichondrium, used as graft material.

\section{Materials and Methods}

Out of all the tympanoplasty surgeries which took place in the Department of Otorhinolaryngology, Mahatma Gandhi Medical College and Hospital from June 2018 to June 2019, only the cases of a mucosal type of diseases with central perforation in the anterior quadrant or large/subtotal central perforations were included in the study. Out of the included cases, 65 cases underwent surgery in group I compared with 80 cases in group II. Group I patients underwent cartilage shield tympanoplasty, while
${ }^{1-5}$ Department of Otorhinolaryngology, Mahatma Gandhi Medical College and Hospital, Jaipur, Rajasthan, India

Corresponding Author: Anuj Kansara, Department of Otorhinolaryngology, Mahatma Gandhi Medical College and Hospital, Jaipur, Rajasthan, India, Phone: +91 9558335203, e-mail: kansaraanuj@ gmail.com

How to cite this article: Ojha T, Kansara A, Yogi V, et al. Comparative Study of Cartilage Shield Tympanoplasty vs Temporalis Fascia Graft Tympanoplasty: A Retrospective Study. J Mahatma Gandhi Univ Med Sci Tech 2019;4(3):71-73.

Source of support: Nil

Conflict of interest: None

group II underwent tympanoplasty with TF as the graft material. Here, patients with intact and mobile ossicular chain (type I tympanoplasty) were found and were included in the study. Patients with posterior quadrant perforation and marginal perforations were readily excluded from this study. Otoendoscopy and pure tone audiometry (PTA) were performed preoperatively and their results were collected and compared postoperatively, which was done at 3 months.

Postauricular (Wilde's) incision was performed in all patients included in our study, after which TF graft was harvested, canal wall incisions were made, after which annulus was lifted to enter the middle ear. All ossicles were checked for their intactness. In the case of encountering ossicular erosion or discontinuity, patients were excluded from our study. Patients in Group I were operated on with conchal cartilage which was harvested with perichondrium. The final thickness of the cartilage was kept at approximately 0.5 $\mathrm{mm}$ and was made thin with the help of the \#15 surgical blade. Cartilage was kept medial to the handle of the malleus. Temporalis 


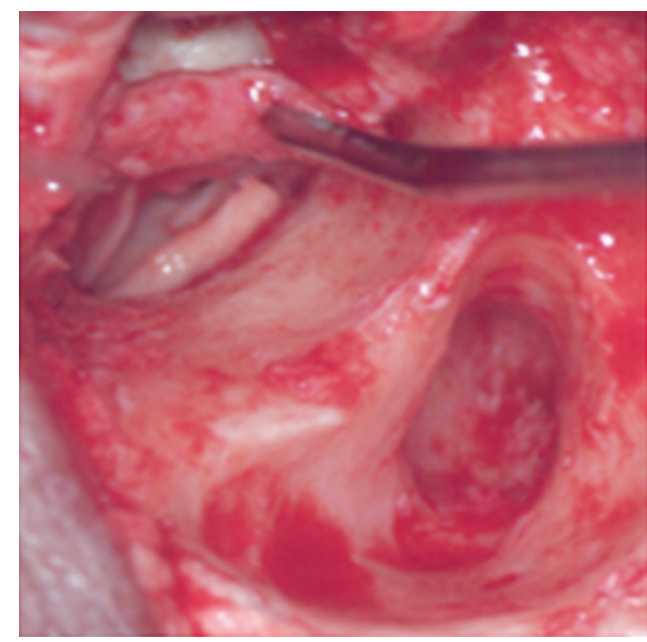

Fig. 1: Cartilage being kept medial to handle of malleus

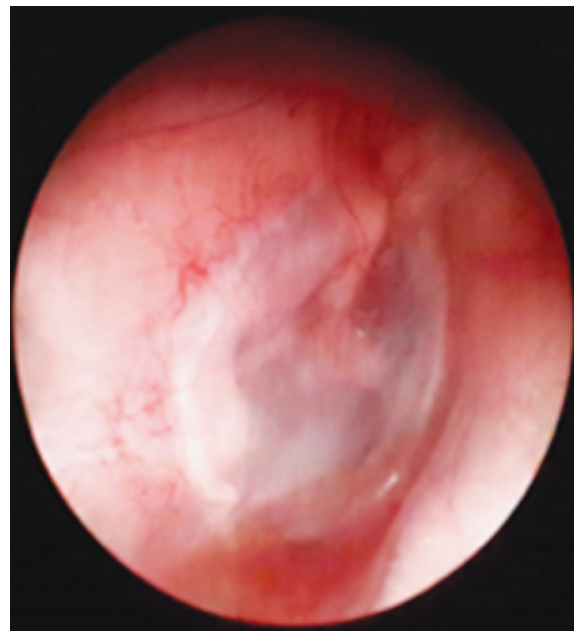

Fig. 3: Postoperative otoendoscopic picture after 3 months of temporalis fascia tympanoplasty

fascia was then placed over this cartilage assembly. To prevent the medialization of the graft, anterior tucking of the TF was done in all the cases. Gelfoam was placed inside the middle ear cavity to help support the cartilage. Gelfoam was also kept laterally in the external auditory canal. In group II patients, TF graft was kept medial to the handle of malleus as an underlay technique, which is strongly suggested by Kartush et al. ${ }^{5}$ Anterior tucking of TF was done. It is necessary to separate the handle of the malleus from the attached remnants of the TM on the handle of the malleus to make the process easy and safe to put fascia medial to the handle of the malleus. Here, Gelfoam was kept both medial and lateral to the grafted TF. At 3 months, the results of preoperative findings were compared with our postoperative results (Figs 1 to 3 ).

\section{Results}

In group I, 62 patients which accounts for a total of 65 ears were operated on with the CST technique. In group II, 80 ears were operated with the TF method of tympanoplasty. Successful graft uptake was seen in 64 cases in group I and 72 cases in group II (Table 1).

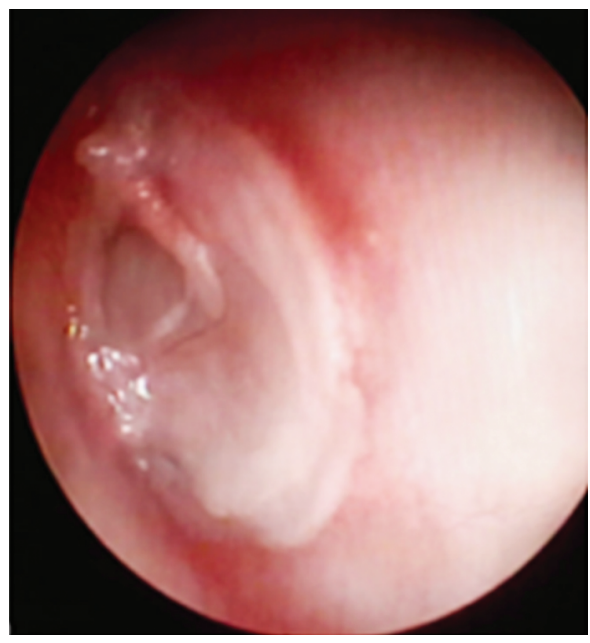

Fig. 2: Postoperative otoendoscopic picture after 3 months of cartilage shield tympanoplasty

Table 1: Showing graft uptake rates of patients in both the groups

\begin{tabular}{lccc}
\hline & Group I & Group II & Total \\
\hline Successful & 64 & 72 & 136 \\
Unsuccessful & 1 & 8 & 9 \\
Total & 65 & 80 & 145 \\
\hline
\end{tabular}

Table 2: Showing comparison of hearing improvement between both groups

\begin{tabular}{llll}
\hline & $\begin{array}{l}\text { Group laverage } \\
\text { hearing gain } \\
(A B G) d B \\
(n=65)\end{array}$ & $\begin{array}{l}\text { Group II } \\
\text { average hearing } \\
\text { gain }(A B G) d B \\
(n=80)\end{array}$ & p value \\
\hline Frequency $(\mathrm{Hz})$ & 15.0 & 14.53 & $\begin{array}{l}0.349, \text { not } \\
\text { significant }\end{array}$ \\
\hline $\begin{array}{l}\text { Mean of } 500, \\
1,000,2,000\end{array}$ & 18.76 & 18.43 & $\begin{array}{l}0.511, \text { not } \\
\text { significant } \\
4,000\end{array}$ \\
14.92 & 15.30 & $\begin{array}{l}0.449, \text { not } \\
\text { significant } \\
<0.0001, \text { sig- } \\
\text { nificant }\end{array}$ \\
\hline
\end{tabular}

In group I, one patient had residual perforation which was found at 3 months' of follow-up. So, the graft take-up rate is $98.46 \%$. Five cases in group II required a revision operation and three cases had small residual perforation that healed with conservative means, so the graft take-up rate for group II is $90 \%$. Statistical analysis (Chisquare test) of graft uptake rates shows a $p$ value of 0.035718 , which was statistically significant. Making graft uptake rates in group I cases better when compared with group II cases. Table 2 shows a comparison of hearing improvement at various frequencies in both groups. Hearing improvement in both groups as evident from the table is almost similar in both groups except at $8,000 \mathrm{~Hz}$ frequency where improvement in group II is seen to be better than that of group I. While at all the other frequencies the difference statistically was not significant between the two groups. The student's $t$-test was used for statistical analysis. Average preoperative Arterial Blood Gas at speech frequencies (mean of 500, 1,000, and 2,000 Hz) in group I was $34.99 \mathrm{~dB}$ and in group II it was $35.48 \mathrm{~dB}$ and average postoperative $A B G$ was found to be $14.97 \mathrm{~dB}$ in group I and 15.88 $\mathrm{dB}$ in group II. Neither lateralization nor medialization of the graft 
was seen among either group in this study. Deterioration of bone conduction indicative of sensorineural hearing loss was not seen in any of the cases in either group. Surgery was uneventful in all patients, i.e., no major complications were noted in any group.

\section{Discussion}

This study was conducted to compare the results of cartilage tympanoplasty with TF tympanoplasty for hearing gain and graft uptake rates. In India, patients were presented with chronic otitis media, have unhealthy middle ear mucosa, and have large, subtotal, or even total perforations of the eardrum. Such cases may require additional support to aid the graft to in turn enhance the chances of graft uptake. In this study, objective evaluation of results of tympanoplasty was noted in patients of mucosal disease (anterior quadrant, large, or subtotal perforations) and a record was made if there was any difference in hearing. In our present study, the graft take-up rate of cartilage shield with perichondrium and with TF came to be $98.46 \%$ which shows similar results to the study conducted by Mundra et al. who used TF/perichondrium with cartilage slice and whose take-up rate was $98.94 \%$. While comparing take-up rates of TF as a graft in our present study to that of Singh et al., the take-up rates were 90 and $93.30 \%$, respectively. While comparing the take up of grafts of TF and cartilage shield, special attention was paid to that of cartilage as it is a relatively thicker graft material, and hearing with this has always been questionable. Aarnisalo et al. ${ }^{12}$ in their study concluded that the placement of cartilage over the medial aspect of the TM will reduce the motion of the TM that opposes the cartilage. The cartilage has a minimal effect over the sound-induced motion of stapes still some changes may occur. Mohamad et al. ${ }^{13}$ suggested the morphological outcomes were better in patients undergoing tympanoplasty using cartilage irrespective of the use of perichondrium when compared with tympanoplasty using TF. However, no statistical significance was seen in hearing outcomes between the two types of grafts. Khan and Parab ${ }^{14}$ using sliced cartilage as a tympanoplasty technique show good anatomical and functional outcomes. Chhapola and Matta $^{15}$ in their study mentioned that cartilage thickness of $<0.5$ $\mathrm{mm}$ and normal TM both have similar acoustic properties when compared with each other. In the present study, better graft uptake rates with the use of cartilage shield method and more hearing improvement, when compared with TF as graft material (Table 3).

\section{Conclusion}

Conchal cartilage in cartilage shield tympanoplasty gives better graft take-up rates as compared to TF used alone. Hearing improvement in terms of mean $A B$ gap is almost equivalent to that of TF tympanoplasty.

\section{References}

1. Lau T, Tos M. Tympanoplasty in children. An analysis of late results. Am J Otol 1986;7(1):55-59. DOI: 10.1016/S0196-0709(86)80035-7.

2. Sapci T, Almac S, Usta C, et al. Comparison between tympanoplasties with cartilage-perichondrium composite graft and temporal fascia graft in terms of hearing levels and healing. Kulak Burun Bogaz Ihtis Derg 2006;16:255-260.
Table 3: Showing comparison of success rates of different graft materials in tympanoplasty

\begin{tabular}{|c|c|c|}
\hline Author & Graft material & Take-up (\%) \\
\hline Dornhoffer $^{6}$ & Perichondrium & 85 \\
\hline Borkowski et al. ${ }^{7}$ & $\begin{array}{l}\text { Cartilage, perichon- } \\
\text { drium }\end{array}$ & 100 \\
\hline Neumann et al. ${ }^{8}$ & Cartilage palisade & 100 \\
\hline Indorewala ${ }^{9}$ & Fascia lata & 95 \\
\hline Indorewala ${ }^{9}$ & Temporalis fascia (TF) & 66 \\
\hline Mundra et al. ${ }^{10}$ & $\begin{array}{l}\text { TF/perichondrium } \\
\text { with cartilage slice }\end{array}$ & 98.94 \\
\hline Singh et al. ${ }^{11}$ & Temporalis fascia (TF) & 93.30 \\
\hline Present study & $\begin{array}{l}\text { Cartilage shield with } \\
\text { perichondrium and } \\
\text { with temporalis } \\
\text { fascia }\end{array}$ & 98.46 \\
\hline Present study & Temporalis fascia (TF) & 90 \\
\hline
\end{tabular}

3. Aggarwal R, Saeed SR, Green KJ. Myringoplasty. J Laryngol Otol 2006;120(6):429-432. DOI: 10.1017/S0022215106000697.

4. Yung M. Cartilage tympanoplasty: literature review. J Laryngol Otol 2008;122(7):663-672. DOI: 10.1017/S0022215108001813.

5. Kartush JM, Michaelides EM, Becvarovski Z, et al. Over-under tympanoplasty. Laryngoscope 2002;112(5):802-807. DOI: 10.1097/00005537-200205000-00007.

6. Dornhoffer JL. Hearing results with cartilage tympanoplasty. Laryngoscope 1997;107(8):1094-1099. DOI: 10.1097/00005537199708000-00016.

7. Borkowski G, Sudhoff H, Luckhaupt H. Autologous perichondriumcartilage graft in the treatment of total or subtotal perforations of the tympanicmembrane. Laryngorhinootologie 1999;78(2):68-72. DOI: 10.1055/s-2007-996833.

8. Neumann A, Schultz-Coulon H-J, Jahnke K. Type III tympanoplasty applying the palisade cartilage technique: a study of 61 cases. Otol Neurotol 2003;24(1):33-37. DOI: 10.1097/00129492-200301000-00008.

9. Indorewala S. Dimensional stability of free fascia grafts: clinical application. Laryngoscope 2005;115(2):278-282. DOI: 10.1097/01. mlg.0000154733.54152.54.

10. Mundra RK, Sinha R, Agrawal R. Tympanoplasty in subtotal perforation with graft supported by a slice of cartilage: a study with near $100 \%$ results. Indian J Otolaryngol Head Neck Surg 2013;65(Suppl 3):1-5. DOI: 10.1007/s12070-013-0673-3.

11. Singh M, Rai A, Bandyopadhyay $S$, et al. Comparative study of underlay and overlay techniques of myringoplasty in large and subtotal perforations of the tympanic membrane. J Laryngol Otol 2003;117(6):444-448. DOI: 10.1258/002221503321892262.

12. Aarnisalo AA, Cheng JT, Ravicz ME, et al. Motion of the tympanic membrane after cartilage tympanoplasty determined by stroboscopic holography. Hear Res 2010;263(1-2):78-84. DOI: 10.1016/j.heares.2009.11.005.

13. Mohamad SH, Khan I, Hussain SSM. Is cartilage tympanoplasty more effective than fascia tympanoplasty? A systematic review. Otol Neurotol 2012;33(5):699-705. DOI: 10.1097/MAO.0b013e318254fbc2.

14. Khan MM, Parab SR. Primary cartilage tympanoplasty: our technique and results. Am J Otolaryngol 2011;32(5):381-387. DOI: 10.1016/j. amjoto.2010.07.010.

15. Chhapola S, Matta I. Cartilage-perichondrium: an ideal graft material? Indian J Otolaryng Head Neck Surg 2012;64(3):208-213. DOI: $10.1007 / \mathrm{s} 12070-011-0306-7$. 